Portland State University

PDXScholar

$1-1-2012$

\title{
From Simple Healer to Doctorally Educated Clinician
}

Lindsey deCampos-Stairiker

Portland State University

Follow this and additional works at: https://pdxscholar.library.pdx.edu/honorstheses

Let us know how access to this document benefits you.

\section{Recommended Citation}

deCampos-Stairiker, Lindsey, "From Simple Healer to Doctorally Educated Clinician" (2012). University Honors Theses. Paper 4.

https://doi.org/10.15760/honors.4

This Thesis is brought to you for free and open access. It has been accepted for inclusion in University Honors Theses by an authorized administrator of PDXScholar. Please contact us if we can make this document more accessible: pdxscholar@pdx.edu. 


\title{
From Simple Healer to Doctorally Educated Clinician
}

\author{
Lindsey deCampos-Stairiker \\ Thesis advisor: Edward Degrauw \\ Portland State University Honors Program
}

Spring 2012 


\begin{abstract}
The profession of physical therapy today is the culmination of various techniques, approaches, and knowledge sources from many different disciplines and philosophies. It is a highly dynamic and progressive field which focuses on incorporating new knowledge and techniques into the established practice: while some aspects can be traced back several millennia, others are the product of evolution and modernization within the field due to discoveries and advances in medical science as well as the needs and demands of the ever changing general population. In order to trace the evolution of the field, this review considered not only the direct progression, but also the cultural history that is associated with its development: the influencing factors in the world that allowed or required the changes that led to the profession as it is today. The evidence, therefore, incorporates contemporary sources throughout the frame of reference: relevant primary and secondary sources from the disciplines of history, medicine, and culture, among others.
\end{abstract}


Table of Contents

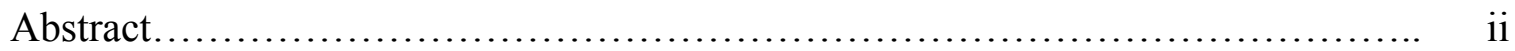

Introduction.......................................................... 1

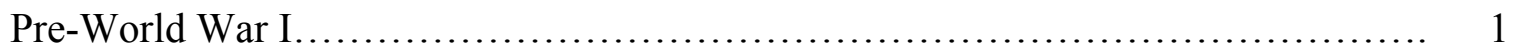

World War I Era...................................................... 6

Post World War I................................................. 9

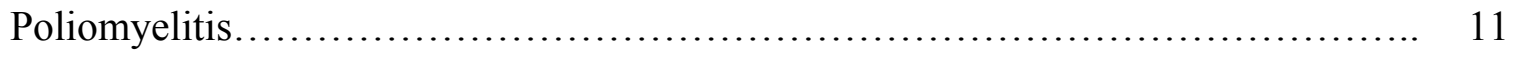

World War II Era...................................................... 13

Post World War II................................................. 15

Competition and the Concept of Supply and Demand $\ldots \ldots \ldots \ldots \ldots \ldots \ldots \ldots \ldots \ldots \ldots \ldots$

Physical therapy as part of a hierarchy.................................. 17

Evolution of the education............................................. 20

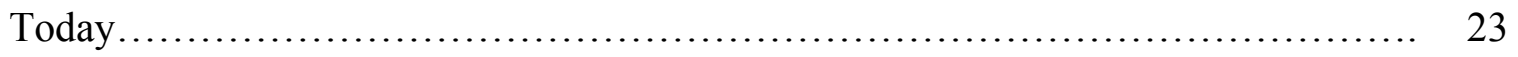

Patient Population and the Workplace.................................. 24

Techniques....................................................... 25

Physical Modalities.............................................. 28

Emotional $/$ psychological duties........................................ 33

Discourse community.............................................. 34

Conclusion......................................................... 37 


\section{Introduction}

The progressive incorporation of discoveries and advancements in knowledge from various disciplines over thousands of years has shaped the evolution of rehabilitation into a distinct entity, which, in its modern form, can be divided into several distinct professional domains. One of the most prominent of these is physical therapy, a profession that evolved to reduce or alleviate pain and restore lost function. Although today many health care specializations are taken for granted, the road which led to the recognition of physical therapy as a specialty practice has been long and difficult for those involved. The purpose of this investigation is to trace the origins of this profession in the United States (U.S.) focusing on the environmental and cultural factors that have caused, and to some extent required, physical therapy to evolve into the specialized modern profession it is today. The development of the profession in the United States will be traced through utilization of relevant primary and secondary sources. This topic is of significant importance to those involved in the field of rehabilitation, physical therapists in particular. Thus, this investigation is written within the community of scholars who are also investigating the origins and evolution of rehabilitation. Literature reviewed includes scholarship with a similar premise (the total history) as well as scholarship that focuses on how a particular period or event has shaped the evolution of the field. Due to the time span considered in this investigation, primarily the early to mid-1900s, the literature reviewed is both historical and recent.

\section{Pre-World War I}

[Physical therapy] drew upon ancient techniques of massage and manipulation, as well as a 
renewed European interest in physical culture and exercise. ${ }^{1}$

Prior to the outbreak of World War I (WWI) the techniques of physical therapy were practiced in their most rudimentary forms, beginning with the subconscious utilization of the natural elements (e.g. light, water, and heat) and continuing with the slow refinement and evolution of intended application. Although not necessarily described or documented in detail, various methods utilized in modern rehabilitation are referenced in historical texts and other sources, perhaps most prominently those of the scholar Hippocrates who is considered the Father of Medicine. ${ }^{2}$ Hippocrates' writings describe his methods for applying the elements to unify the four humors of the body and emphasize the importance of the body as a whole needing to be in good health in order to heal itself. ${ }^{3}$ In contemporary practice, a variety of methods were used in order to improve personal comfort rather than specifically advance overall health in that before WWI disability was not considered a medical or social problem. ${ }^{4}$

A survey of the literature identifies a number of therapeutic modalities that have their origins in ancient times and became more specific and refined prior to the advent of WWI. These include familiar techniques such as hydrotherapy and massage, techniques more specific to certain cultures, and common activities that were recognized to have a specific set of therapeutic benefits with regard to rehabilitation. Each of these will be discussed briefly below.

Among the first unconscious therapies, hydrotherapy is a method that has been heavily used in healing practice throughout the history of humankind. Scholars today find references to it in the works preserved from various notable writers and cultures: Homer, Hippocrates, Egypt (the healing powers associated with the Nile River), Rome, Greece, and more. From these

\footnotetext{
${ }^{1}$ Larkin 1332

${ }^{2}$ Matziari et. al. 93

${ }^{3}$ Garrison 99

${ }^{4}$ Matziari 93, Gritzner 39
} 
writings it is clear that water (traditionally spring water) was used not only for an intended specific temperature but also for its compositional and mineral concentration. ${ }^{5}$ A high water temperature, for example, not only increased circulation and metabolism, but assisted in relaxation and could serve as a preparation to massage and/or manipulation. In ancient times, the practice of bathing for the treatment of wounds was often referred to as "curing". 6

Manipulation of various body parts has been most readily available to humankind. In general, the goal of manipulation is to free restrictions in soft tissue and joints. From the earliest times this process could be applied by self or outside application through acts such as "cracking" various joints or stretching muscles. ${ }^{7}$ The development of outside manipulation came with time and the origins were diverse: from the technique of back-walking in ancient Asian culture to the modern profession of chiropractic which relies heavily on a wide variety of manipulative techniques.

Electric currents, x-rays, and ultraviolet light are often utilized in modern physical therapy, although the respectability of electrotherapy has been questionable throughout its history due to the exploitation by quacks and charlatans. ${ }^{8}$ Its origin lies with the discovery and eventual application of magnetic attraction to the re-education of muscles. Subsequent scientific progress allowed electrotherapy to be established on a rational and scientific basis, and the utilization of this technology as a specialty practice began in the late nineteenth century with the practitioners (a very limited number of physicians who had chosen to embrace electrotherapy as a treatment source for certain ailments) calling themselves 'electrotherapeutists'. 9 After the WWI era, physicians utilizing this method changed their name again to "physical therapy

${ }^{5}$ Cimbiz 245, "The Cottage Physician" 505

${ }^{6}$ Richardson 2

${ }^{7}$ Paris "A History" 67

${ }^{8}$ American Physical Therapy Association 2

${ }^{9}$ Gritzner 39 
physicians' and eventually joined the larger group that was already calling themselves a similar name. $^{10}$

From the sun come two ancient forms of heliotherapy: thermotherapy and phototherapy, which began with the unintentional harnessing of the power of the sun to heal various maladies, whether physical or psychological. It is now understood that the psychological benefits come from the exposure to the blue light wave that is contained in full spectrum light (such as that of the sun), and are related to the synthesis and utilization of the neurotransmitters serotonin and melatonin. ${ }^{11}$ In comparison, the physical aspects of the sun's healing ability were linked to the heat experienced on the body and the subsequent activation of various bodily components and processes. As knowledge progressed, these healing powers were replicated through various means such as heated water, lights, cloth, etc., which were applied to the body directly or through an intermediary in order to promote blood circulation and relax muscles. ${ }^{12}$

Due to the aversion of the Chinese culture to shedding blood, the practice of physical therapy has been highly prominent in the treatment of injured people throughout their history. ${ }^{13}$ The Chinese practice of physical therapy incorporates various methods common in the early development of physical therapy: dry cupping, massage, and physical exercise, the latter two of which are the common basis of the practice of modern U.S. physical therapists.

Born of the act of rubbing a painful area, the medical application of massage has become crucial in today's healing world. ${ }^{14}$ An innate instinct, the evolution and utilization of this method are seen throughout history: the Chinese culture in 3000 B.C.E., textual references from 460 B.C.E. in the writings of Hippocrates, to the Romans, Greeks, and Swiss and finally to the

\footnotetext{
${ }^{10}$ Gritzner 62

11 Degrauw

${ }^{12}$ Gieck 1200

13 Ackerknecht 47, American Physical Therapy Association 1

${ }^{14}$ Wade 593
} 
acceptance of massage as a worthy method of treatment in $1812 .^{15}$ Unsurprisingly, the utilization of massage was quickly linked to the muscle re-education of pre-physical therapy practices.

The origin of the Olympic Games, considered by many to be a gathering of the finest athletes in the world, is rooted in the ancient Greek interest in sport competition. The intense interest and focus of ancient Greek culture on sports led to the development of gymnasiums; a place where the competitors trained under the instruction of coaches. ${ }^{16}$ A large number of the most notable gymnasiums and coaches were located in Sweden and, understandably, the coaches gained a vast amount of knowledge regarding massage and rehabilitation through responding to the injuries of their athletes, and as their knowledge and ability to rehabilitate progressed, so did the knowledge and techniques of the pre-physical therapy world. ${ }^{17}$ Additionally, Hippocrates is known to have used physical exercise as a method of health preservation and the cure for some diseases in combination with heat, water, and massage. ${ }^{18}$

Prior to the sixteenth century, wooden legs and walking sticks were the only artificial support options for those with injuries to the lower limbs that had required amputation or, more likely later on due to higher survival rate, hindered movement. With the introduction of ligature of blood vessels, a larger number of patients began to survive the process of amputation. ${ }^{19}$ In later years, the desire of the government to return people with injuries to independent life created increased support for utilizing artificial limbs which encouraged further development of artificial support methods as well as rehabilitation techniques. This in turn helped the physical therapy profession become involved in longer term and larger scale patient care with both surgeons and

\footnotetext{
15 American Physical Therapy Association 1

${ }^{16}$ Ackerknecht 53

${ }^{17}$ McMillan 201

${ }^{18}$ McMillan 199, Larkin 1331, Behneman 393, Hazenhyer 191

${ }^{19}$ Eldar 1021
} 
prosthetists.

For the most part, the development of each specialized branch of rehabilitation therapy was independent, although the idea of "specialty" implies an interdependency. ${ }^{20}$ Regardless of the degree of interdependency, all of the modalities fell subject to being discredited due to quacks at one time or another until a technological or scientific advancement established the necessary basis to restore the credibility of its use. ${ }^{21}$ Once established, the branches generally continued their independent development until need required that they be brought together or combined for the purpose of healing patients suffering from multiple or acute conditions. For example, prior to the conclusion of WWI, the conscious scientific application of physical therapy had been limited to a certain degree to the orthopedic field. ${ }^{22}$

\section{World War I era (approximately 1914-1918)}

...although the components of modern physical therapy have been known for centuries, 'the Surgeon General of the United States Army, at one stroke, completed their amalgamation when he described physiotherapy as 'physical measures such as ... hydro, electro, mechano therapy, active exercises, indoor and outdoor games, and passive exercises in the form of massage'. ${ }^{23}$

The long-standing sentiment, that nothing good can come of war, is expressed by people of many cultures. However, this is countered by the competing sentiment that "non-destructive consequences may result from the devastation of war" as "efforts to counteract tragedy result in

\footnotetext{
${ }^{20}$ Gritzer XV

${ }^{21}$ Major 1021

${ }^{22}$ McMillan 9

23 "The Emergence of Our Profession" 11
} 
growth. ${ }^{24}$ In many fields the latter appears to hold true as the most rapid advancements in technology or discovery are frequently fueled by necessity. WWI is a prime example of this phenomenon in the medical field, as demonstrated in many specialties, particularly in rehabilitation, as it allowed an explosion in both knowledge and experience, as well as the more accurate and intelligent application of both. ${ }^{25}$ The beginning of the professionalization of modern physical therapy in the U.S. has been traced consistently to the WWI era, a time during which the need to rehabilitate and return injured soldiers to either duty or civilian life became among the highest priorities of the U.S. military. Prior to this time, people with disabilities (both genetic and acquired) had been left to cope as best they and their families could, while soldiers injured in the line of duty generally had been returned to civilian life in their current state to live on a disability pension provided as compensation for their service. ${ }^{26}$ This is perhaps surprising to U.S. citizens today, a time when rehabilitation of soldiers is expected and demanded, but prior to WWI, rehabilitation was limited and primarily grew as a money saving technique by the army. The reality is that with thousands of soldiers returning from duty, the long term cost-to-benefit ratio of providing rehabilitation versus disability pensions greatly favored the former. Thus, the army originally expanded its rehabilitation services in order to reduce the financial strain that otherwise would have been incurred by having to fund long term hospitalization or disability pensions to the thousands of returning soldiers. ${ }^{27}$ Preparation for providing direct rehabilitation was undertaken to accommodate expected patients, and a number of buildings and beds were funded by the army, although the actual number of patients far outstripped all predictions. ${ }^{28}$

Previous advances and expansion in surgery and orthopedics increased the chance that

\footnotetext{
${ }^{24}$ Eldar 1019, Granger 14

${ }^{25}$ McMillan 5

${ }^{26}$ Marble 2

${ }^{27}$ Marble 12

${ }^{28}$ Marble 21, 23
} 
patients would survive operations and amputations, and the need for medical supervision of recovery quickly outstripped the supply of surgeons available. ${ }^{29}$ Due to the increase of the often extreme workload demanded of physicians, many were required to delegate tasks to the personnel under their command. With the most convenient delegates being the women who were already assisting the physicians, the unique situation created by the war allowed the opportunity not only for the advancement of women in the military, but also the increased integration of rehabilitative services. ${ }^{30}$ Such women, who became known as Reconstruction Aides", were generally between twenty-three and forty years of age and were required to have had a grade school education and, for the profession, to have a theoretical and practical knowledge of physiotherapy (as it was then called and is still called today in most other countries) with a general understanding of hydrotherapy and massage in particular. Although employed by the military, they were considered to be civilian workers as they did not enter hostile areas. ${ }^{31}$ Initially, the training of the Reconstruction Aides, considered preparation to become specialty masseurs who could treat muscle and joint conditions, was overseen by orthopedic surgeons, in particular the army surgeon Dr. F. B. Granger.$^{32}$ Throughout the war era, the unification of the individual healing components became more solidified, with the modalities most frequently utilized including: the ultraviolet ray, deep therapy lamps, muscle training, massage, and exercise. ${ }^{33}$ As the call for Reconstruction Aides increased, the women who answered the call were most often nurses or special education teachers. By the end of the

${ }^{29}$ Eldar 1020, Larkin 1333

${ }^{30}$ Gritzner 8-9

* Those involved with rehabilitation within the military were given the title 'Reconstruction Aides' while those outside the military were referred to by a variety of titles such as 'Physiotherapy Technicians' or 'Physical Therapy Aides'.

31 Taylor 151

${ }^{32}$ Eldar 1020, Gritzner 44, "Recollections and Reminiscences" 22

33 "Recollections and Reminisces" 37, Richardson 2 
war, an estimated eight hundred Reconstruction Aides had laid the foundation for the future of an entire profession, and for some time thereafter they continued to operate as they had during the war: implementing and overseeing the treatments prescribed by physicians who retained a significant amount of control in during that time. ${ }^{34}$ However, while their medical colleagues acknowledged them for their expertise, most saw physical therapy as little more than an adjunct to medicine and surgery that dealt with the rehabilitation of wounded soldiers. ${ }^{35}$

\section{Post WWI}

By 1918, a significant change had taken place: the duty of supervising the Reconstruction Aides changed from the military's orthopedic physicians to belonging to the 'electrotheropeutists' (also known as physiotherapists and physical therapy physicians). ${ }^{36}$ In 1921, with the events of WWI concluding and soldiers being discharged from service, the services provided by the military through the Reconstruction Aides began to move to civilian and government organizations: “many found employment in civilian hospitals, physicians' offices, hospitals of the (then) Veterans Bureau, or the Public Health Service."37 Until this time, the Reconstruction Aides had been almost exclusively women. While at first consideration this may be surprising, a deeper inspection has identified a variety of influential factors for this phenomenon. Of perhaps foremost importance is that the Women's Rights Movement was continuing to gain support during the WWI era, in part due to the circumstances and needs created by the war, causing an increasing number of women to abandon the societal norm of domesticity. With most able-bodied men involved directly with military combat, women

\footnotetext{
${ }^{34}$ Coulter 601, Larkin 1336, Moffat 1063

35 "Recollections and Reminiscences" 36

${ }^{36}$ Gritzner 40

37 American Physical Therapy Association 25, "The Beginning of the Association" 51, Marble 27-29
} 
assumed the roles once occupied by the men in the general community, as well as filling the work force positions that were created by the effects of war. However, as the demand for rehabilitative services continued to increase, the work force expanded to include both women and men which caused the American Women's Physical Therapeutic Association (established 1921) to become the American Physiotherapy Association (1922) and eventually the American Physical Therapy Association in 1946 (APTA) in order to more accurately reflect the change in practitioners. $^{38}$ Additionally, in 1929 the American Association of Electro-Therapeutics and Radiology joined with the APTA. ${ }^{39}$ The formation and continuation of these groups occurred for several reasons: the desire to maintain friendships made during the war, continuing education purposes (discussing relevant topics, research on techniques to improve patient care, etc.), and, eventually, to more effectively publicize physical therapy. ${ }^{40}$ Although the explosion in demand for physical therapy as part of the rehabilitation process was being phased out of direct military control, the value of the practice had left a mark on the public that was not to be forgotten:

"The war demonstrated ... that even severe injury need not lead to serious disability, provided suitable treatment following the care of the wounds can be given. Good primary surgery and good nursing, of themselves, do not yield results which can be considered satisfactory.",

Thus, the favorable results experienced by the application of physical therapy to war victims created a continued and accelerating demand for such treatments to continue to be offered after the conclusion of the war, but also to be expanded to treat the ailments of the general public

\footnotetext{
${ }^{38}$ American Physical Therapy Association 25, Paris “A History” 70, Gritzner 176

${ }^{39}$ Gritzner 63

40 "The Beginning of the Association" 51-52

${ }^{41}$ American Physical Therapy Association 25
} 
wherever possible. ${ }^{42}$ In addition to the obvious physical improvement in the patients, the moral sentiment and economic advantage to rehabilitation were undeniable. ${ }^{43}$ Many of these sentiments grew out of the attitude of the rehabilitated soldiers themselves: they were independent members of society who had a chance at a relatively "normal" life after the war. No longer were they required to rely on charity or the small government disability pension for which they were eligible, as their predecessors had. ${ }^{44}$ The world had always had the components of physical therapy, but now they were being specifically identified, combined, developed, and utilized at a very rapid rate during one of the most pivotal time periods in U.S. history.

\section{Poliomyelitis}

Between the two world wars the interest in rehabilitation faded, except for a brief period in the 1930s, following the epidemic of poliomyelitis. ${ }^{45}$

The purpose of physical therapy during the time between the two World Wars was the scientific re-education of muscles and tissues through application of the elements, as well as through muscle training and massage. ${ }^{46}$ The 1930s and 1940s saw changes in the application of physical therapy techniques: an increase in acute care and, prior to the outbreak of World War II (WWII), a large reduction in military-related treatment. ${ }^{47}$ In addition to providing continuing rehabilitation "after acute infections and in the after-treatment of fractures and nerve injuries", rehabilitation played a large role in the treatment of poliomyelitis victims. ${ }^{48}$ The poliomyelitis techniques, introduced to the United States by the Australian nurse, Sister Elizabeth Kenny, were

\footnotetext{
${ }^{42}$ McMillan 9

${ }^{43}$ Major 1021

44 Thurber 68

${ }^{45}$ Eldar 1020

${ }^{46}$ Bentley 469

${ }^{47}$ Marble 3

${ }^{48}$ McMillan 5
} 
completely contradictory to the previous methods used for treatment; rather than complete immobility after a patient contracted the disease, this new method prescribed heat through warm wraps, motion to re-educate muscles, and education about the disease and its after-effects for the patients. $^{49}$ The outbreaks of poliomyelitis left many people paralyzed or severely disabled, and patients proved to be very responsive when these methods were used for muscle retraining, as they were directed at treating the effects of the virus, rather than the virus itself. ${ }^{50}$ Although these methods were viewed suspiciously at first, within a short period of time the new methods had become the norm. ${ }^{51}$

In addition to completely revolutionizing the treatment of acute conditions by discouraging the immobilization of patients, the Sister Kenny methods also lent strength to solidifying the legitimacy of physical therapy. The polio virus had attacked tens of thousands of people, sparing no particular class or group, and the huge demand for treatment created a hole in the medical field that no other profession was capable of filling at that time. ${ }^{52}$ Further, it allowed physical therapists to begin to introduce the idea of "pre-habilitation" which would condition the general population in order to prepare men for military combat as well as improve work force efficiency and "usefulness" in society. ${ }^{53}$ The increasing possibilities for the application of physical therapy also cast light onto the fact that physical therapy training programs needed to make an understanding of muscles and their actions a part of the curriculum as therapists were increasingly required to personalize treatment programs. $^{54}$

Poliomyelitis marked a spike in the fading general interest in rehabilitation which had

\footnotetext{
${ }^{49}$ Gritzner 90, Moffat 1066

${ }^{50}$ Neumann 484

${ }^{51}$ Plack 2

${ }^{52}$ Neumann 479, 488

${ }^{53}$ Plack 2, Marble 16

${ }^{54}$ Neumann 485
} 
occurred between the first and second world wars, but all three events were monumental in the development due to the increased number of patients and, thereby, general awareness. ${ }^{55}$ It is interesting to speculate whether the election of Franklin Delano Roosevelt to president of the United States was a contributing factor for the increased attention that was given to those with disabilities (Roosevelt had contracted poliomyelitis prior to becoming president). ${ }^{56}$ Various historical records and investigations support this hypothesis, as the years during and following Roosevelt's presidency saw increased research of disabling diseases, treatment of those with disabilities (both military and civilian), as well as a continued expansion of the physical therapy profession. Not only was the profession returning to public awareness, the practitioners, particularly those involved with the polio virus, were developing methods and techniques that would be maintained and further refined as time passed. The developments were chronicled in the journal published by the APTA, Physical Therapy Review, and are often considered by therapists to be the origin of physical therapy specific literature. ${ }^{57}$

\section{World War II era (approximately 1939-1945)}

The field of physical therapy emerged from the great demand for physical rehabilitation resulting from worldwide medical crises, and continuing demand for services stimulated further growth of the field. ${ }^{58}$

The beginning of the 1940s once again saw some (albeit limited) preparation by the army

for the increased demand for rehabilitation that would soon become a reality. ${ }^{59}$ The increasing demand for soldiers soon outstripped the supply and, with no sign of slowing soon, attention

\footnotetext{
${ }^{55}$ Eldar 1020

${ }^{56}$ Plack 4

${ }^{57}$ Neumann 482

${ }^{58}$ Plack 2

${ }^{59}$ Marble 31
} 
changed from the time and money consuming task of enlisting, educating, and training new soldiers to the reconditioning and re-deployment of those previously trained. ${ }^{60}$ Treatment of polio victims and rehabilitation of soldiers who could not be returned to duty continued, but were of lower priority during this time. Current physical therapists were asked to enlist as Red Cross reserves, and training was reduced from the length of time that had become accepted between the two World Wars, with a greater emphasis on hands-on clinical practice which focused on the treatment of amputation, conditions of the nervous system, and combat injuries. ${ }^{61}$

In the first year of WWII, physical therapists were finally granted military status, as it had been demonstrated that even civilian employees were often subject to various risks, both in the U.S. and overseas. In late 1942, Congress approved physical therapists to be eligible for relative military rank and in 1944 physical therapists achieved full commissioned status. ${ }^{62}$ Even with these changes, therapists were not part of the army draft and, as in WWI, the difficulty in meeting the demand for therapists was severe; however this time it was due in part to the fact that therapists were required in the rehabilitation of soldiers as well as continued rehabilitation of civilian polio victims. ${ }^{63}$ Fortunately, the relationship between rehabilitation and the resulting functional capacity of all types of patients was apparent and the profession was able to gain financial support from several private and governmental sources in order to increase training programs and incentives for new physical therapists. ${ }^{64}$ The shortage of physical therapists during these decades also allowed the creation of a physical therapy assistant position. Physical therapy assistants are technicians whose tasks are comparable to those of the original Reconstruction Aides, with their purpose being to allow the physical therapist more time for other tasks,

\footnotetext{
${ }^{60}$ Marble 35

${ }^{61}$ Marble 31, Taylor 153

62 Taylor 151

${ }^{63}$ Marble 41

${ }^{64}$ Neumann 482, 485
} 
specifically, “...decision making, problem solving, and patient management" ${ }^{65}$

While WWI can be considered the birth of what would become modern physical therapy, the growth that took place during WWI and between the two World Wars allowed physical therapy to "[come] into its own" ${ }^{66}$ WWI had laid the foundation, establishing an outline of the duties of a physical therapist; the intermediary time had allowed development and growth of techniques and knowledge base, and by the 1940s, a routine and regimen had been established (although, of course, growth continues to occur). By the end of WWII, physical therapy had become an established and recognized independent profession in the medical field which specialized in the application of: “...massage, graduated exercise, weight and pulley exercises and remedial exercises, galvanic stimulation to re-educate muscles, short wave diathermy and wax baths" ${ }^{67}$ Also at this time, the realization that physical rehabilitation is not something that suddenly starts, but rather has a variety of benefits throughout patient care began to sink in for therapists, the public, the government, and the army. ${ }^{68}$

\section{Post World War II}

Following WWII, continued armed conflicts meant a continued need for rehabilitation of wounded military combatants to restore the muscles to maximal usefulness which allowed progressive development of the services offered. ${ }^{69}$ WWII differed from WWI in that the medical field emphasized a comprehensive approach that relied on an interdependency of medical services to provide the quickest return to independent life. ${ }^{70}$ An obvious example of this was the practice of amputation which increased during the war years: as techniques continued to be

\footnotetext{
${ }^{65}$ Plack 7, Taylor 170

${ }^{66}$ Blackwell 21

${ }^{67}$ Richardson 8, Blackwell 21

${ }^{68}$ Marble 56

${ }^{69}$ Eldar 1020

${ }^{70}$ Eldar 1021
} 
refined and success rates improved, the relationship between surgeons, prosthetic providers, and physical therapists became increasingly interlocked. All amputations required further surgery and/or healing, and physical therapists were increasingly called upon to assist in training patients to perform tasks with their prosthesis and strengthen muscles. ${ }^{71}$ During this time, there was a predominant use of massage, although the utilization of modalities and other previously mentioned techniques was also common place. ${ }^{72}$ The decreased emergency response focus allowed for an increase in the growth and quality of care and also enabled therapists to answer the demand for off-site treatment.

Over time, positive sentiments and support toward the results obtained through rehabilitative programs reinforced both the physical and psychological benefits due to the independence obtained. $^{73}$ It is therefore unsurprising that rehabilitation and other care for military veteran personnel was soon expected to be provided by the government. Physical therapists treating army patients therefore continued to provide care to avoid a premature return to duty or to society. ${ }^{74}$

\section{Competition and the Concept of Supply and Demand}

The security of such a position depended on the recognition and acceptance of other physicians: willingness not to treat patients themselves, but instead refer them to a specialist.... ${ }^{75}$

The impact of the relationship between supply and demand can be seen in all aspects of modern culture. The effects of this relationship were heavily illuminated by the establishment of the first Reconstruction Department by the United States Army in 1918 (consisting of

\footnotetext{
${ }^{71}$ Dougherty 758

${ }^{72}$ Blackledge 20

${ }^{73}$ Thurber 68

${ }^{74}$ Marble 76

${ }^{75}$ Gritzner xvi
} 
Physiotherapy, Occupational Therapy, and Curative Workshop Divisions). With the demand for Reconstruction Aides far outpacing the supply, the solution was condensed intense training periods for prospective aides with increased benefits upon completion and employment. ${ }^{76}$ Additionally, the supply and demand relationship (well known to be the predominant force in determining salaries) is one reason that the Reconstruction Aides (and later physical therapists) often received higher benefits than others with comparable training periods. ${ }^{77}$

As efforts to control health care costs become increasingly important, there will be a "stronger focus on the advantages of prevention". 78 The gradual change that is occurring in population subgroups will soon produce an unbalanced general population with far more older people than younger. The impact of the desire to keep people, both young and old, at a top performance level means that methods to prevent injuries will be sought not only by the private citizen wishing to improve his or her physical condition but also by the employer who wishes to reduce the amount that must be paid for workers compensation. ${ }^{79}$ The physical therapy profession has continued to experience a higher demand for service than its competitors in the changing demographics because it is "a profession that has responded to the health care needs of the population it serves" rather than attempting to force the population to conform to what it offers. $^{80}$

\section{Physical therapy as part of a hierarchy}

After development of the profession took off in the early 1900s, feeling the need to prove the worthiness of rehabilitative services to function as an independent profession has been an almost universal sentiment among therapists. Although there was no denying the usefulness of

${ }^{76}$ McMillan 10, "Recollections and Reminiscences" 23

${ }^{77}$ Rothstein 1056

${ }^{78}$ APTA 383

${ }^{79}$ APTA 383

${ }^{80}$ APTA 384 
the services provided, many physicians felt that rehabilitation by non-physician clinicians was more of a "passing fad", and that once the number of patients requiring treatment had returned to a manageable number, the rehabilitative components included in treating patients would be reclaimed by physicians, particularly the orthopedic surgeons. ${ }^{81}$ Thus, the physical therapy physicians of the post WWI era (and even to a certain degree in the present day) were faced with the challenge of convincing physicians that their services were not only useful but better than the services provided by other competitors. They were competing not only against the desire of physicians to rehabilitate their patients themselves, but also those physicians who continued to link physical therapy with quackery as they had in the pre-WWI era. Assistance from the American Medical Association (AMA) proved invaluable to the gradual acceptance of the profession, and the AMA provided the suggestion for physical therapy to be utilized:

"...with drugs and surgery, but never as the sole treatment" and "only as an adjunct to other forms of treatment... [and] ... only prescribed by a physician trained in this area" ${ }^{82}$

Additionally, the AMA encouraged physicians only to refer patients to physical therapy physicians with approved accreditation to further reduce the ties between physical therapy and quackery.

With the continued development of the medical field as a whole, the 1930s saw the introduction of physical therapy departments into hospitals and a continuous increase in support for the services provided by the profession. At this time, primary care physicians retained the role of recommending physical therapy as a treatment and would suggest a general method of treatment to the physical therapist, although the actual selection and implementation of treatment was left to the latter. Additional changes in contemporary medicine that occurred during the post

\footnotetext{
${ }^{81}$ Gritzner 65

${ }^{82}$ Langnecker 90, Gritzner 65
} 
war era included the popular movement toward specialization. This phenomenon required that official boundaries be established between occupations which in turn led to a somewhat clearer division of labor. ${ }^{83}$ However, the movement toward specialization also highlighted the interdependency of medicinal occupations causing the strategy of physical therapists to change in order to achieve recognition as a distinct and independent profession:

"Rather than persuading others to use their methods, they now claimed that only they were competent to perform certain tasks. Although physicians could perform basic physical therapy techniques, more difficult procedures required specialists." ${ }^{, 84}$

Due to the ongoing struggle of physical therapists to prove the efficacy of their methods, much of the original support for the utilization of physical therapy and the connection between this growing profession and the medical world came from people who were generally not physical therapists, but rather other medical personnel who had witnessed its benefits. ${ }^{85}$

Additionally, modern physical therapy seems to be caught in several ongoing battles which have called into question the legitimacy of the claims of the profession. For example, many chronically ill patients find themselves referred to physical therapy by their physician. At times these physicians have exhausted all other options, and while physical therapy is able to help many of these patients, it is not a "cure all" as assumed by some or expected by patients. ${ }^{86}$ Therefore, while many methods and theories have been firmly established, there is still the need of the profession to publicize not only its existence, but also what it does and how it does it. Patients often remember only the "toys" a therapist used as part of a treatment, while the physicians are more focused on the physical components: "in the mind of the public, the term

\footnotetext{
${ }^{83}$ Gritzner xvi

${ }^{84}$ Larkin 1329, Gritzner 69

${ }^{85}$ Gritzner 91

${ }^{86}$ Behneman 393
} 
'physical therapy' signifies electricity, lamps, and machinery ... in the mind of the physician, however, its true definition remains that of body mechanics, massage, and postural training". ${ }^{87}$

\section{Evolution of the education}

"The demands of practice should govern the content and design of the curricula." 88

In very few professions does this statement seem more accurate than when describing the evolution of the education required to become a physical therapist (or the title used at the respective time period). Adjusted to reflect the controllable and uncontrollable demands and variables at a particular moment in time, physical therapist education has been dynamic, adjusted to reflect the constraints imposed by time, available resources, and demand.

At the outbreak of WWI, there were no schools or courses specific to rehabilitation services. ${ }^{89}$ However, with the increased demand for such services, the training of Reconstruction Aides quickly increased in importance and training programs began. While originally the training was minimal and tended to be 'on the job' through "in service training, including lectures and clinical demonstrations by physicians", the heightened demand for high quality service caused the government to establish the first formal training program in $1918 .{ }^{90}$ The earliest programs were "intensive training in anatomy, physical education, and Swedish massage". ${ }^{91}$ The short training period of three to four months was somewhat counterbalanced by accepting only applicants who came from physical education programs with a high standing. ${ }^{92}$ In addition to the military programs, training courses were established at colleges and

\footnotetext{
${ }^{87}$ Behneman 394

${ }^{88}$ Rothstein 1055

${ }^{89}$ Coulter 601

90 "Recollections and Reminiscences" 24, Moffat 1063

91 "Recollections and Reminiscences" 24

92 "Recollections and Reminiscences" 24, Plack 3
} 
universities that had the facilities and capacity to host such courses. The number of schools willing or capable to host these training courses were few and more than half of the 1,600 physical therapists trained for WWI graduated from military training programs. ${ }^{93}$ A person of foremost importance in the development of the profession, and in particular the education, was Mary McMillan, and a review of a variety of written recollections by former Reconstruction Aides identified a common sentiment: acknowledgement of her importance and influence in their training and later practice as physical therapists. Although trained in Great Britain, McMillan is traditionally considered to be the first U.S. physical therapist, having served with the U.S. military in WWI (and the subsequent events) as well as having been monumental in the development of training programs and schools for physical therapists. Additionally, her influence on the profession as a whole is evident in other ways, ranging from being a founding member of the APTA to her advocacy of the importance of the work of physical therapists. ${ }^{94}$

During the 1920s and 1930s, the education requirements developed with respect to the desire of physical therapy technicians to acquire military status equal to that of the Army Nurse Corps. ${ }^{95}$ In 1928, the American Physiotherapy Association (APA) established the first minimum requirements of education in this profession: "a 9-month, 1,200 hour program of instruction, with the prerequisite for admission being graduation from a recognized school of physical education or nursing" ${ }^{96}$ The time constraint experienced by both the educators and students meant that the training remained a certificate program with the emphasis on technical training rather than knowledge. In 1939, the APA relinquished the setting of standards for education to the AMA

\footnotetext{
${ }^{93}$ Gritzner 102

${ }^{94}$ Paris "Interests of the Patient" 1546

${ }^{95}$ Gritzner 99

${ }^{96}$ Plack 4
} 
and, through the AMA, an emphasis for standardization throughout the country emerged. ${ }^{97}$

As the demand for service increased again with the outbreak of WWII, the requirements to become a physical therapist were once again reduced. Nine month certificate courses were offered, those courses which had begun to offer degrees were reduced from three years to two and a half years in length, and people were allowed to begin training at a younger age. ${ }^{98}$ However, by 1955 , approximately eighty percent of all physical therapy students were enrolled in degree programs. ${ }^{99}$

Reflective of the changes observable in the profession itself, the education of the physical therapist has evolved throughout the course of history, becoming increasingly challenging. One of the most influential factors in the changes to education is the desire of the profession to achieve academic legitimacy within standards that reflect the immediate knowledge needs of practitioners as part of the ongoing attempt to obtain full recognition of independent practice. ${ }^{100}$ In less than one hundred years, what was once a group of women holding certificate degrees has evolved into a doctoral degree available to both men and women. Furthering the claim of physical therapists to become a doctorate level profession was the continued utilization of physical therapy assistants (a position introduced while physical therapy was still a masters program). The opinions and support regarding the arrival of a doctoral degree have been mixed: while some practitioners anticipated improvements such as increased respect from health care professionals and insurance representatives as well as the potential for autonomous practice, or "practice without referral", others had doubts regarding whether or not these changes would

\footnotetext{
${ }^{97}$ Plack 5

${ }^{98}$ Plack 5, Blackledge 21

${ }^{99}$ Neumann 483

${ }^{100}$ Moffat 1063, Board of directors 522
} 
actually be realized. ${ }^{101}$

Unsurprisingly, advances in technology are visible in the education process through the utilization of what is now "everyday technology" (recorders to record and re-listen to lectures, computers for in depth study and investigation and PowerPoint presentations, etc.), as well as interactive computer programs that expose students to real life situations, and introduction into the type of computer technology the newly hired therapist is likely to encounter in the field (specifically programs that allow patient charts, notes, and schedules to be visible to all involved medical personnel). ${ }^{102}$ Further, advances in medical technology such as artificial replacements for body parts have also expanded the knowledge base a successful physical therapist must have. Together, the advances in technology, knowledge, and medical care as well as a dynamic and more complex patient population have led to a higher standard of skill and depth of knowledge required of practitioners. ${ }^{103}$

\section{Today}

Physical medicine is both the oldest and newest form of therapy. ${ }^{104}$

Modern physical therapy has much the same goal as it did from the beginning: to assist people with various disabilities and illnesses to overcome or work within their limitations while continuing to live their lives. ${ }^{105}$ This includes patients with chronic debilitating conditions as well as conditions that "may not be entirely disabling in nature [but] may hinder the individual's functioning". ${ }^{106}$ Current practice is generally considered to be the culmination of various sources

\footnotetext{
${ }^{101}$ Plack 1

${ }^{102}$ Wojciechowski 18

${ }^{103}$ Plack 2

${ }^{104}$ Wade 593

105 Gritzner 12

${ }^{106}$ Gieck 1200
} 
of knowledge brought together by need and general demand and is composed of four primary components: massage, therapeutic exercise, electrotherapy, and hydrotherapy. ${ }^{107}$ Reflective of the development of techniques and expansion of knowledge, treatment settings are very diverse, having expanded in both location and number in order to offer treatment where it is needed.

\section{Patient Population and the Workplace}

The purpose of the fledging profession was to assist in the protection of the U.S. by rehabilitating trained soldiers when possible and enabling those unable to return to combat to become as independent as possible in their everyday lives. Today, the techniques that have been developed are applied to countless situations and the recipients are able to seek treatment for a variety of reasons. However, demographics of the current population show that the older population far outnumbers the younger and, in response, research is being conducted to investigate how to best address these changes. With the general awareness that functional capacity decreases with age, the emphasis on early prevention through therapeutic and other measures is becoming increasingly publicized. Related to this awareness, the observation that performing specific exercises seems to help slow the progression of or reduce symptoms of some physical and mental illness has led to increasing research in this area. ${ }^{108}$ Although this knowledge has become much more recognized by the general population, people were aware of these effects long ago as shown in a work from the 1950s:

"Physical therapy in many instances can retard the aging process not only by affecting the individual physically but also mentally, as his outlook on life is sometimes changed."

While the original place of the physical therapist was wherever the wartime rehabilitation centers were (either military, government institutions, or private facilities), when wars were not

\footnotetext{
${ }^{107}$ McMillan 11

108 Thane 1110

${ }^{109}$ Gieck 1199
} 
the primary dictating factor, treatment locations moved into the community. ${ }^{110}$ Obvious places were hospitals, but as time went on, an increasing number of physical therapists began to leave the hospital in favor of establishing their own practice or joining that of another medical professional (other therapists, physicians, etc.), for reasons related to "a lack of upward mobility and a higher intensity workload than that found in other institutions". ${ }^{11}$ Thus, many of the therapists found in the hospital are new graduates, although new and experienced therapists have been found in various other institutions such as schools, nursing homes, welfare departments, and private offices, among others, since the mid-nineteenth century. ${ }^{112}$

The efforts to obtain the ability to practice without referral correlated directly with the increasing number of physical therapists working outside the hospital. ${ }^{113}$ Although the ability to establish independent practice was achieved in 1982, this advancement was initially met with a notable amount of physician resistance due to their desire to retain direct control of care decisions regarding their patient populations.

\section{Techniques}

While the education of physical therapists has become more standardized, the methods of practice have become standardized only to a certain degree. There is the overarching orthodox treatment, but within the U.S. it is interesting to note the differences in practice between regions: certain regions appear to emphasize practice through a combination of manual techniques, exercises, and modality use while other regions gravitate toward a single one of the aforementioned methods. ${ }^{114}$ The utilization of a particular method over others could be one reason that the legitimacy of physical therapy to stand alone has been a question of concern

\footnotetext{
${ }^{110}$ Marble 1

${ }^{111}$ Koska 32

112 Hazenhyer 193

113 Gritzner 129

${ }^{114}$ Neumann 485
} 
among various groups (medical personnel, insurance agencies, etc.): neglecting other methods often leaves the duty of performing certain techniques to other medical personnel which suggests that physical therapy may not be standardized enough to be considered an independent practice. ${ }^{115}$ Whether or not one manner of treatment is favored over another, therapists, like any health care provider, should be capable of adapting their treatment to the individual needs of each patient, identifying what needs to be done and then executing it (task centered working). ${ }^{116}$ The modern combination of movement techniques and modalities is used to: "[relieve] pain and muscle spasm, [increase] range of motion, [strengthen] muscles, [relieve] muscular imbalance, [stretch] and [remove] scar tissue and adhesions, and [provide] an easier way of life with less bodily effort". 117

Therapeutic movement and exercises are divided into two domains, passive and active. The primary goal of passive movement of the joint by an outside source is to prevent adherence by the formation of scar tissue surrounding an injury and/or in order to increase or maintain range of motion. Passive exercise requires that the patient not actively contract muscles but allows for preparation for the following stages of recovery. ${ }^{118}$

- Mobilization: "the forcing of the full range of motion at a joint" is a technique that is used to break adhesions that are limiting movement at a joint. ${ }^{119}$ This is often done incrementally, such as slowly increasing the mobility of a joint through repeated exercise and stretching, physical, hands-on movement of the joint through its respective kinematic motions, or in more extreme conditions, in one fell swoop under anesthesia by a licensed surgeon (as this is extremely painful due to the literal ripping of adhered tissue) that generally allows the patient

\footnotetext{
${ }^{115}$ Moffat 1065

${ }^{116}$ Paris “A History” 75, Richardson 14, Neumann 486

117 Gieck 1200

${ }^{118}$ Hofkosh 1480

${ }^{119}$ Cyriax 25
} 
to have more range of motion earlier in the recovery process. ${ }^{120}$ Physical therapy is based on incremental improvement, and if such a circumstance arises as to necessitate mobilization by a surgeon, the methods of incremental improvement are even more crucial in order to prevent re-adherence of the tissue. Mobilizations are graded I-V based on the degree of force as well as where in the joint's individual capsular range it is applied; grade $\mathrm{V}$ is manipulation. ${ }^{121}$

- Manipulation: maneuvering of a body part done by the hands. Although it is possible to selfmanipulate to a degree, in general the most beneficial manipulation is a passive process for the recipient in which someone else moves a joint and the surrounding tissues at varying amplitudes and speeds for therapeutic purposes. ${ }^{122}$ While manual therapy has been readily available, its advertised professional application within the field of physical therapy is more recent due to misleading, and often erroneous, claims made by chiropractors during the 1930s. Wishing to avoid being among those discredited, physical therapy as a profession did not greatly advertise manual therapy to the general public, although the techniques continued to be utilized: "he [James Cyriax; a renowned orthopedic physician] also trained physiotherapists and advocated that they, more than the physician, were the correct person to perform manipulative techniques". ${ }^{123}$ Stressing the hands-on, or "human dimension" of manual therapy, Paris, a physical therapist in the post WWII era, emphasized that integrating manual therapy into everyday practice helped give physical therapists an advantage for attracting patients, and manual therapy slowly regained acceptance as a component of physical therapy treatment. ${ }^{124}$ In spite of this, only some states allow physical therapists to do mobilizations.

\footnotetext{
120 deCampos

121 Smith

122 Paris "A History" 66

${ }^{123}$ Paris "A History" 71

${ }^{124}$ Paris "Interests of the Patient" 1543,1541
} 
Generally, in American physical therapy practice, mobilization is a technique that is a non-thrust method while manipulation is a term that encompasses thrust techniques. ${ }^{125}$

Active movement at a joint by the conscious will of the patient attempts to maintain range of motion by preventing formation of scar tissue. Treatment by active movement increases the capacity to utilize a muscle by lengthening and strengthening it (post-operatively) and/or prepares for post-operative side effects (pre-operative). ${ }^{126}$ Post-operatively, ability is increased by either increasing the resistance (load) or the number of repetitions. As Matziari notes: "in concert with Hippocrates' belief, if an untrained individual starts with difficult exercises, this would cause injuries to his muscles...". ${ }^{127}$ Thus, both the patient and the therapist must take care to ensure that the muscle is exerted at a rate and amount so as to not lose through re-injury what has been gained by either surgery or previous exercise.

\section{Physical Modalities}

There are a number of specific treatment domains that have become an integral part of rehabilitation including, hydrotherapy, massage, electrotherapy, etc. Each of these provides specific therapeutic benefits and long term recovery goals. The application of hydrotherapy today is becoming more universal and refined. In its simplest form, water, generally considered to be the very basis of life, is used to sustain a person by keeping the body hydrated so that it is capable of continued performance. Some of the most frequent applications of water are the cleaning of wounds (in liquid form), and to reduce or relieve pain (liquid or solid form). ${ }^{128}$ The use of aquatic exercises is now frequently prescribed for a variety of maladies for the purpose of strengthening and/or reducing their impact on the everyday functioning of the patient. Research

\footnotetext{
${ }^{125}$ Paris "A History" 67

${ }^{126}$ Cyriax 25, McMillan 203

${ }^{127}$ Matziari 99

${ }^{128}$ Matziari 96
} 
by a variety of sources has shown that an aquatic component is particularly beneficial to patients who experience pain under normal gravitational conditions due to the different properties of water (buoyancy, warmth, pressure, etc.) and it is therefore frequently combined with other therapeutic modalities. ${ }^{129}$

Massage, or soft tissue mobilization, continues to be a large part of physical therapy, although primarily in outpatient settings. The different types of massage (superficial versus deep) are taken into account when treating, depending upon the need of the individual patient. Superficial massage helps relieve muscle spasm and is often used before cold therapy and many other treatments. ${ }^{130}$ Depending on the geographical region, this type of massage may be a favored method of loosening the muscles further than what can be achieved by stretching in the same amount of time, generally after strengthening exercises are completed for the session. In contrast, deep tissue massage is used to disturb muscle spindles for a deeper healing treatment. The rational for this type of massage is based on the idea of creating a situation which stresses the muscle sufficiently so that it engages in more active healing, directing and allotting more resources to the area. Metal and plastic tools molded into specific shapes have been developed which allow deep tissue massage and a higher degree of healing without over-exerting the therapist. $^{131}$

Electrical stimulation is one method that continues to develop due to the advances in technology that are often not directly related to the medical field. It was discovered that both low and high voltage electrical stimulation can be used to stimulate sensory and motor nerves in order to reduce pain, edema, and muscle atrophy as well as promote healing and blood flow. ${ }^{132}$

\footnotetext{
129 Silva 13, Cimbiz 245

${ }^{130}$ Sheldon 1478

${ }^{131}$ Larlee

132 Haltrecht 573
} 
This can be achieved through a variety of methods, such as transcutaneous electrical nerve stimulation (TENS). Methods such as TENS generate an electrical current which flows through wires and electrodes placed on the skin which then affects the muscles and nerves under them by taking advantage of the flow of electrons to produce heat, as well as cause chemical changes and an electrical gradient which then causes a muscle contraction. ${ }^{133}$ Different intensities and wave form patterns can be used to achieve different effects, either clearly visible (such as muscle contraction) or below sensory awareness without visible effects. ${ }^{134}$

Technologies such as $\mathrm{x}$-ray have also been greatly developed and are applied to a large variety of treatments and settings, particularly in the medical field. Primary uses of x-ray include anti-inflammatory purposes and pain reducing capabilities as well as improved functioning and circulation, as x-ray affects the absorption of the tissue. ${ }^{135}$ However, while the many applications of x-ray are incredibly useful, they are not notably prevalent in most physical therapy settings in the United States (although they are used more frequently overseas). Instead, this treatment is likely to be used in conjunction with physical therapy.

Today, the application of heat continues to be a prominent form of treatment used to stimulate circulation, organ function, and absorption of products of inflammation. ${ }^{136}$ Ultrasound is often used to produce deep heat in muscles by taking advantage of the force of friction either during the acute period of an injury or for the treatment of chronic issues. ${ }^{137}$ The heating of the muscle allows for increased range of motion due to neuromuscular relaxation directly caused by the heat, as well as an increase in cell response which promotes healing; ultrasound heat penetrates twice as deep as surface/skin heat packs. Likewise, the use of cold therapy continues

\footnotetext{
${ }^{133}$ Smith

${ }^{134}$ Billig 1479, Rubine

${ }^{135}$ Rossi 1493

${ }^{136}$ Gieck 1199

${ }^{137}$ Haltrecht 573
} 
to be important in the healing process by means of pain relief and the restoration of function. The presence of cold results in a local "reduction in tissue temperature [which] tends to minimize the amount of hemorrhage, edema, and muscle spasm". ${ }^{138}$ Although the utilization of cold therapy has been traced to the earliest recordings, the knowledge that it is most beneficial in the first 24 to 48 hours (due to its ability to deeply penetrate the local area) after which heat becomes more beneficial is a newer development. ${ }^{139}$

The short and long term utilization of artificial support devices is widespread in the United States. The creation and improvements made to the various support devices over the last fifty years is remarkable, and these devices have dramatically increased the functional ability of the user. The job of the physical therapist in both pre-habilitation and rehabilitation increasingly encompasses the task of selecting and fitting patients with and then teaching the correct use of the devices.

- Braces are among the most common devices as they are used to provide protection and/or support of a joint. ${ }^{140}$ Some prevent movement of a joint in specific directions while others prevent the joint from moving at all. The former is likely to be used in response to relatively minor injury, reducing the risk of further injury while the patient recovers, either naturally or through a planned program. The latter is likely to be utilized after a more major injury or surgery if a complete lack of movement is necessary for healing. Braces are available for almost any body part and many are available for easy purchase by the general public, although others can be obtained only through physician prescription.

- Ambulatory aids such as crutches and walkers are objects used to support the weight of the body in normal movement due to injury or other weakness that would otherwise impair it.

\footnotetext{
${ }^{138}$ Sheldon 1477

139 Sheldon 1477

${ }^{140}$ Neill 1475
} 
Crutch training has become a routine part of pre-habilitation for surgical procedures that require the use of crutches post-operatively. ${ }^{141}$ Frequently, the use of crutches or a walker is temporary, and either of these are used until the patient is able to walk without risk of reinjury.

- Prosthetics continue to improve with time: a person with an amputated leg who previously would have been limited to a wooden replacement can now be offered an artificial device that has been carefully developed so as to be stable and, perhaps most importantly, functional in everyday life. Additionally, prosthetics are no longer limited to the lower extremities; devices are now available for many body parts such as arms and hands. The financial support for prosthetic work is also financially efficient long term, as the monetary impact on the government and society correlates inversely with the ability of affected person to function independently. ${ }^{142}$ Further, dramatic developments are fueling the simulation of natural motions by implementing computers and motors to help mimic normal motion in legs and hand prosthetics. ${ }^{143}$

\section{Emotional/psychological duties}

Whereas time limitations caused by outside factors limited long term patient-therapist interaction during the development of the profession, in the current age the amount of times a therapist sees a patient may be few (such as immediately post-surgery) or ongoing (such as outpatient strengthening). Perhaps something for which the new therapist is not adequately prepared at the completion of education is the degree to which he or she must also be involved in the patient's emotions. People who feel insecure or helpless -- either mentally or physically -are not likely to progress quickly in their journey toward achieving their full physical capacity.

\footnotetext{
${ }^{141}$ Neill 1476

${ }^{142}$ Marble 78

${ }^{143}$ Smith
} 
Thus the therapist must provide emotional support in addition to directing the physical aspects of the process. ${ }^{144}$ This may be as simple as making the sessions enjoyable through conversation (so that the patient will not only perform well during the session but will at least attempt any outside work they are assigned or be distracted from their pain), but the physical therapist may be required to assume the tasks of encouraging and inspiring a patient who is focused only on disability, pain, or a guarded prognosis. As Gieck observes: "for example motivation by a physical therapist may help change the attitude of pessimism of an amputee in a wheelchair to one of optimism about a normal life with an artificial limb". ${ }^{145}$ Communication is therefore one of the most important aspects of therapy: communication with both medical colleagues and with the patient on a comprehensible level. ${ }^{146}$ Throughout the average career, a physical therapist will need to treat a number of disabilities for which the long term recovery possibility is limited. In these and less extreme situations, it was recognized early on that the therapist must be understanding and empathetic yet not pitying of the patient. The return on this emotional investment will vary between therapists, but many will experience a deep-rooted sense of gratification in watching the gradual improvement of the patient after having puzzled out how best to assist him or her on the road to recovering optimal potential. ${ }^{147}$

\section{Discourse Community}

Based on the incredible developments and continued growth within rehabilitation, it is surprising to discover that there has been relatively little scholarship that directly focuses on the overall history of the profession. Instead, much of the scholarship revolves around the recurring

\footnotetext{
${ }_{144}^{144}$ McMillan 203, Mas 1501, Snow 959

${ }^{145}$ Gieck 1199

${ }^{146}$ Board of Directors 524-525

${ }^{147}$ Hazenhyer 194
} 
issues of: how physical therapy was used during a specific point in time, education of the practitioners, and the development of the Association in concurrence with the profession (much of the writings reflecting development of the profession were published in the journal of the Association). However, when combined, these individual texts allow for a detailed history of the profession to be compiled. Perhaps one reason for the lack of "large picture" retrospection is that the people who are most qualified to record such a history (those working within the field), are instead focused on the future and encouraging growth. They acknowledge and value the ground that they have gained over the course of the last century in particular, but also recognize how much further they still have to go. Rehabilitation may be recognized as a crucial part of certain recoveries and treatments, but clarifying which specific practitioner will implement the rehabilitation is still challenged to a certain degree within the medical world. An exploration of past and current literature indicates that the continued development within this community is rooted in scholarship on subjects such as practice and treatment techniques as well as research and discovery.

Although large picture retrospection is limited, it does exist and works range from a limited overview of history (usually in the context of looking back followed by looking forward) to a brief exposition about a particular epoch. The work produced by joint or individual efforts is often presented at milestone events sponsored by the APTA or in landmark issues of the journal published by the APTA. The forefront community of scholars recently pursuing this subject matter is, unsurprisingly, individuals within the physical therapy community who are held in high esteem within the APTA and the rehabilitation community, including J. Echternach, S. Paris, M. Plack, and J. Rothstein. Previous communities can also be identified such as P. Dougherty, M. Moffat, S. Paris, and J. Rothstein, working in the late 1990s, and G. Beard, J. 
Cyriax, J. Coulter, F. Granger, I. Hazenhyer, H. Rusk, and A. Watkins, working in the midtwentieth century. Within the earlier communities, particularly the one of the mid-twentieth century, many of the scholars are more well-known due to their ground breaking work or support that encouraged advancement of the field and profession. Of foremost importance in this regard are Drs. Cyriax and Granger, who have both been recorded as having been monumental in their support for the recognition of rehabilitation as a specialization that could -- and should -function independently of other medical professions.

Within the scholarship produced and presented in such medias, it is clear that there is less disagreement than when compared with other scholarly communities, as the starting material of this subject leaves little to be debated due to the variety of past works that document the history in some manner. Instead, the real questions and points of interest in current times seem to revolve around achieving an understanding of the cultural and social factors that lent themselves to the development of the profession and how the amalgamation of scholarship can be applied to the future. The primary sources explain what occurred and, at times, how, but much of the why has been minimized or disregarded. From one perspective, this is unsurprising; the medical personnel of the time were more focused on recording their methods (documentation which could be referenced to facilitate future improvements) rather than the specific reasoning behind what they were doing; objective documentation which could then continue and expand, allowing a change to occur in everyday clinical practice. Monumental events in U.S. history create obvious starting points for research and analysis because it is during the years surrounding these events in which the most change (and scholarship) is produced. While some works provide an in-depth look into relevant cultural factors merely as an integral part of the writing, other works prove to be more of a challenge and these aspects are obtained or inferred through careful 
analysis. One example of this is military texts. While, in general, these do not hold physical therapy as the primary subject matter, careful reading casts light on cultural components that influenced the field directly (the influence of the war itself on the goals of the profession, how the profession was treated during wartime, changes in standards during war, rehabilitation goals and needs, etc.) as well as reveal how much the structure of the rehabilitation world was influenced by the system and hierarchy of the military itself. ${ }^{148}$ In other texts that document a general overview of the history of medicine, such as that of Major, rehabilitation is a minor section. ${ }^{149}$ But the fact that it is present at all can be seen as an advancement: it was becoming recognized as its own entity, and sections devoted to rehabilitation are becoming increasingly detailed.

Once works that directly reference rehabilitation are analyzed to superficially understand the changes, it is possible to pursue texts that give insight into the particular cultural factors that caused or encouraged changes or developments to occur: perhaps a public sentiment or opinion, contemporary events, or a new discovery or application of a pre-existing technique to established treatment. $^{150}$

\section{Conclusion}

Physical therapy is not a new system of recognizing and treating diseases... It is simply a method of treating disease and injury with the aid of physical agents ... [serving] to relieve symptoms and speed recovery. ${ }^{151}$

Originating from a set of tasks delegated to subordinates, physical therapy has developed

\footnotetext{
${ }^{148}$ Marble

149 Major

${ }^{150}$ Gritzner, APTA

${ }^{151}$ Gieck 1199
} 
in response to specific treatment needs into an independent profession that continues to grow exponentially in both respectability and public awareness. While the most rapid development of the profession can be seen to correlate directly with the World Wars due to the desire to recapacitate injured soldiers, the development that has occurred throughout the decades has benefited not only those for whom it was intended, but also the general public throughout their lifespan and is even beginning to benefit those animals entrusted to human care. ${ }^{152}$ Rehabilitation by physical therapy continues to develop due to a variety of reasons including increasing general awareness, progression of the medical field, demand, research, cost efficiency, and the desire of both the general public and the government to maintain a population that is functioning to the full extent of each individual's abilities. ${ }^{153}$ Even with all these factors influencing and shaping the progression of the profession, it is easy to observe that although the manner of achieving the desired outcome has evolved dramatically, the basic concepts can be traced through history through several millennia of history to the earliest records which emphasize that "exercise, hot baths, and a good sleep ... offer vitality and health". ${ }^{154}$

As can be seen through the evolution and extended applications of physical therapy in both acute and chronic conditions, the ability of physical activity to improve quality of life or prevent the onset of pathological conditions is something about which the medical field is becoming increasingly aware. Continually striving to increase efficiency, health service providers have become much more cognizant of the impact rehabilitation departments can have on the health care system of a country. ${ }^{155}$ Additional rehabilitation through physical therapy (meaning longer or more frequent treatment sessions) during patient stay not only reduces length

\footnotetext{
152 Haltrecht 573

${ }^{153}$ Marble 95

154 Matziari 100

${ }^{155}$ Eldar 1022
} 
of stay, but "... significantly improves mobility, activity, and quality of life". ${ }^{156}$ While the desire to improve efficiency not only is considered to reflect a well-functioning hospital, it appears that the reduced length of stay related directly to increased physical therapy services would also reduce the overall cost for the patient, hospital, and community. ${ }^{157}$ As noted by Granger and later Langnecker, the economic gain to the hospital is by their ability to admit a larger number of people in relation to their increased turnover rate, while the increased gain to the community is by the corresponding decrease in overall cost (directly related to a greater number of people sharing the costs). ${ }^{158}$ Through retrospective analysis and prospective consideration, the profession continues to support the APTA Vision Statement for Physical Therapy 2015: "[to become] the preferred choice for the prevention and treatment of impairment, functional limitation, and disability related to the neuromusculoskeletal system."159 But in setting such a goal, the profession must take care to "maintain a status, knowledge base and scope of practice which altogether ensure a credibility of professional purpose and competence in a changing healthcare environment", for without maintaining what it has achieved, the profession cannot hope to move forward. ${ }^{160}$

We must lead the profession through uncharted paths, yet we must continue to walk in the paths of those who have provided the legacy of which we may be justly proud. ${ }^{161}$

\footnotetext{
${ }^{156}$ Peiris 1490

${ }^{157}$ Peiris 1497

${ }^{158}$ Langnecker 90

${ }^{159}$ Campbell 1060

${ }^{160}$ Richardson 13

${ }^{161}$ Moffat 1066
} 
Bibliography: From Simple Healer to Doctorally Educated Clinician

Ackerknecht, Erwin Heinz. A Short History of Medicine. Baltimore: Johns Hopkins UP, 1968. Print.

Alic, Margaret, Brenda Lerner. "Physical Therapy." Gale Health Collection. Detroit: Gale, 2010. Online.

APTA Ad Hock Strategic Planning Task Force. "American Physical Therapy Association Environmental Statement.” Physical Therapy 72.5 (1992): 378-94. Print.

Ayres, Samuel. "Physical Therapy." California and Western Medicine XXVII.1 (1927): 90-91. Print.

Beard, G. "Foundations for Growth. A Review of the First Forty Years in Terms of Education, 
Practice, and Research.” The Physical Therapy Review 41 (1961): 843-61. Print.

“The Beginning of the Association." Physical Therapy 56.1 (1976): 50-51. Print.

The Beginnings: Physical Therapy and the APTA. Washington, D.C.: APTA, 1979. Print.

Behneman, H. "Physical Therapy -- Criticisms and Suggestions." California and Western Medicine 41.6 (1934): 393-96. Print.

Bentley, Marion H. "Physical Therapy: the Relation of Physical Therapy to Medicine." The American Journal of Nursing 26.6 (1926): 469-71. Print.

Billig, Harvey. "Electrotherapy." Encyclopedia of Sports Medicine. New York: Macmillan (N.Y.), 1971. 1478-479. Print.

Blackledge, Catherine. "Life during Wartime." Physiotherapy Frontline 12.11 (2006): 20-23. Print.

Board of Directors. "Standards for Basic Education in Physical Therapy." Physical Therapy 52.5 (1972): 521-25. Print.

Cimbiz, Ali, Vahdettin Bayazit, Hasan Hallaceli, and Ugur Cavlak. "The Effect of Combined Therapy on Pain in Various Chronic Diseases." Complementary Therapies in Medicine 13 (2005): 244-50. Print.

The Cottage Physician, for Individual and Family Use. Springfield, MA: King-Richardson, 1901. Print.

Coulter, J. S. "History and Development of Physical Medicine." Archives of Physical Medicine (1947): 600-02. Print.

Cyriax, James. Massage, Manipulation and Local Anesthesia. London: Hamilton, 1941. Print. deCampos, Juliet, MD. Phone interview. 2011

Degrauw, Ed. "Brain and Cranial Nerves." Anatomy and Physiology II. Portland State 
University, Portland. 2011. Lecture.

Dougherty, P. J. "Wartime Amputations.” Military Medicine 158.12 (1993): 755-63. Print.

Eldar, Reuben, and Miroslav Jelić. "The association of rehabilitation and war." Disability and Rehabilitation 25.18 (2003): 1019-023. Print.

“The Emergence of Our Profession.” Physical Therapy 56.1 (1976): 11-14. Print.

Galdston, Iago. Social and Historical Foundations of Modern Medicine. New York: BrunnerMazel, 1981. Print.

Garrison, Fielding H. An Introduction to the History of Medicine, with Medical Chronology, Suggestions for Study and Bibliographic Data. Philadelphia: Saunders, 1966. 99. Print.

Gieck, Joe. "Retardation of Aging." A Manual of Electrotherapy. Ed. Arthur L. Watkins. Philadelphia: Lea \& Febiger, 1968. 1199-201. Print.

Granger, F. B. “The Development of Physiotherapy.” Physical Therapy 56.1 (1976): 13-14. Print.

Gritzer, Glenn, and Arnold Arluke. The Making of Rehabilitation: a Political Economy of Medical Specialization, 1890-1980. Berkeley: University of California, 1985. Print.

Haltrecht, Helaine. "Physical Therapy." Canadian Veterinary Journal 41 (2000): 573-74. Print. Hayhurst, Chris. “The State of Physical Therapy Research.” PT in Motion 3.2 (2011). Print.

Hazenhyer, Ida M. "Physical Therapy as a Career.” Bios 17.4 (1946): 191-97. Print.

"Healthcare Savvy. What to Expect from Physical Therapy." Consumer Reports on Health 17.9 (2005): 10-11. Print.

Hofkosh, Jack. "Exercise - Weight Training.” Encyclopedia of Sports Medicine. New York: Macmillan (N.Y.), 1971. 1480-481. Print.

Koska, Mary T. "Rehabilitation Growth Fuels PT Shortages.” Hospitals 63.5 (1989): 32. Print. 
Krusen, F. "Historical Development in Physical Medicine and Rehabilitation during the Last Forty Years.” Archives of Physical Medicine \& Rehabilitation (1969): 1-5. Print.

Langnecker, Harry L. "Physical Therapy.” Medicine Today XXVII.1 (1927): 90-91.

Larkin, Gerald. "The Emergence of Para-Medical Professions." Companion Encyclopedia of the History of Medicine. Vol. 2. New York: Routledge, 1993. 1329-1349. Print.

Larlee, Chante, DPT. Personal interview. 2011.

Major, Ralph. A History of Medicine. Vol. 2. Springfield: Charles C Thomas, 1954. Print.

Mass, Rafael. "Occupational Therapy." Encyclopedia of Sports Medicine. New York: Macmillan (N.Y.), 1971. 1501-502. Print.

Matziari, Chrysoula. “A Commentary on Hippocrates' Views about Selective Issues on Exercise, Health and Diet." Studies in Physical Culture and Tourism 8 (2011): 93-101. Print.

McMillan, Mary. Massage and Therapeutic Exercise. Philadelphia: Saunders, 1925. Print.

Moffat, Marilyn. "Will the legacy of Our Past Provide Us With a Legacy for the Future?." Physical Therapy 74.11 (1994): 1063-6. Print.

Neill, William. "Braches, Crutches.” Encyclopedia of Sports Medicine. New York: Macmillan (N.Y.), 1971. 1475-477. Print.

Neumann, Donald A. "Polio: Its Impact on the People of the United States and the Emerging Profession of Physical Therapy." Journal of Orthopaedic and Sports Physical Therapy (2004): 479-92. Print.

Paris, S. "A History of Manipulative Therapy Through the Ages and Up to the Current Controversy in the United States." The Journal of Manual \& Manipulative Therapy 8 (2000): 66-77. Print.

Paris, S. "In the Best Interests of the Patient." Physical Therapy 86.11 (2006): 1541-553. Print. 
Peiris, Casey L., Nicholas F. Taylor, and Nora Shields. "Extra Physical Therapy Improves Patient Outcomes." Archives of Physical Medicine and Rehabilitation 92 (2011): 1490500. Print.

Plack, Margaret M. "The Evolution of the Doctorate of Physical Therapy: Moving beyond the Controversy." Journal of Physical Therapy Education (2002). Print.

"Recollections and Reminiscences of from Former Reconstruction Aides." Physical Therapy 56.1 (1976): 22-40. Print.

Richardson, Barbara. "The Way Forward--How and Why?." Advances in Physiotherapy 1.13 (1996): 13-6. Print.

Richardson, Janice. A Study of the Forces and Influences Leading to the Development of Specialization in the Profession of Physical Therapy in the United States. Diss. University of Pittsburg, 1983. Ann Arbor: University Microfilms International, 1983. Print.

Rossi, Folco. "X Ray.” Encyclopedia of Sports Medicine. New York: Macmillan (N.Y.), 1971. 1492-493. Print.

Rothstein, Jules. “A Matter of Degree.” Physical Therapy 76.10 (1996): 1054-6. Print.

Rubine, William, PT. Personal interview. 2011.

Rusk, Howard. "The Growth and Development of Rehabilitation Medicine." Archives of Physical Medicine \& Rehabilitation (1967): 463-66. Print.

Selcon, H. "The First Century of Mechanical Electrotherapy." Physiotherapy 87.4 (2001): 20809. Print.

Sheldon, Keith. "Cold Therapy." Encyclopedia of Sports Medicine. New York: Macmillan (N.Y.), 1971. 1477-478. Print. 
Silva, Luciana E., Valeria Valim, Ana Pessanha, Leda M. Oliveira, Samira Myamoto, Anamaria Jones, and Jamil Natour. "Hydrotherapy Versus Conventional Land-Based Exercise for the Management of Patients with Osteoarthritis of the Knee: A Randomized Clincial Trial." Physical Therapy 88.1 (2008): 12-21. Print.

Smith, Marvin, DPT. Personal interview. 2012.

Snow, William. "The Relation of Physical Therapy to Arthritis." The New England Journal of Medicine 229.26 (1943): 959-65. Print.

Strickland, Benjamin A. "Physical Medicine in the Army." Archives of Physical Medicine (1947): 279-36. Print.

Taylor, Richard R. "Chapter V. Dietitians, Physical Therapists, and Occupational Therapists." Medical Department, United States Army [in World War II]... Washington: Department of the Army, Office of the Surgeon General, 1975. Print.

Thane, Pat. "Geriatrics." Companion Encyclopedia of the History of Medicine. Vol. 2. New York: Routledge, 1993. 1093-1112. Print.

Thurber, Evangeline. "Rehabilitation of World War I Veterans in District No. 12." Pacific Historical Review 15.1 (1946): 68-76. Print.

United States of America. Army. Office of Medical History. Rehabilitating the Wounded: Historical Perspective on Army Policy. By Sanders Marble. Falls Church, Va.: Office of Medical History, Office of the Surgeon General, 2008. Print.

Vogel, Emma. “The Beginning of 'Modern' Physiotherapy.” Physical Therapy 56.1 (1976): 1521. Print.

Watkins, Arthur L. “A Note On Physical Therapy.” Annals of Surgery 117.6 (1943): 911-14. Print. 
Wade, B. "Progress Report." Archives of Physical Medicine (1949): 593-99. Print.

Wicksteed, Jane Honora. The Growth of a Profession: Being the History of the Chartered Society of Physiotherapy, 1894-1945. London: E. Arnold, 1948. Print. 